\title{
Time to walk the talk: embracing the built environment to promote physical mobility
}

\author{
Lawrence D Frank, ${ }^{1}$ Heather A McKay²
}

\begin{abstract}
In Outliers, Malcolm Gladwell argued that 'success'-whether it be sporting, financial or health-related-resulted not from genetic mutation but from an environment that provides some substantial advantage. ${ }^{1}$ In this Warm up, we draw attention to the Built Environment as an overlooked determinant of health. ${ }^{2-4}$ Remember, the built environment-the places in which people live, work and play-is the setting for your patients to execute your activity prescription!
\end{abstract}

\section{PROMOTE ACTIVITY FOR UTILITARIAN NEEDS}

People who rely only on 'recreational or leisure time' to battle the epidemic of physical inactivity usually lose. Time to recreate is constrained by many factors including increasing time required to travel and work. ${ }^{5}$ On the other hand, those who walk to the bus or train, who walk to shops in their local community and who bike to work are likely to meet physical activity guidelines. ${ }^{67} \mathrm{~A}$ built environment that supports walking, biking and transit over driving can help to structure daily patterns to include regular physical activity. A transit trip is an interrupted walk trip-one study found that, compared with drivers, transit users were 3.4 times more likely to get recommended physical activity through walking. ${ }^{8}$ Health professionals can engage with urban planners and local politicians to help ensure that neighbourhoods are walkable and transit supportive. This means there are destinations in the neighbourhood connected with a high-quality pedestrian environment that allows residents to accomplish daily activities nearby. ${ }^{9} 10$ Shops

\footnotetext{
${ }^{1}$ Schools of Environmental Health and Community and Regional Planning, University of British Columbia, Vancouver, Canada

2Departments of Orthopaedics and Family Practice, Centre for Hip Health and Mobility, University of British Columbia, Vancouver, Canada

Correspondence to Dr Lawrence D Frank, Schools of Environmental Health and Community and Regional Planning, University of British Columbia, \# 433-6333 Memorial Road, Vancouver, Canada V6T 1Z2; Idfrank@interchange.ubc.ca
}

and services, healthy food sources, parks and open space all connected with quality sidewalks enable walking for all age groups. Older adults require safety, seating and appropriately timed pedestrian street crossings. As a very bright 90 -year-old said at a recent meeting of city engineers, urban geographers and health professionals, 'It's not complicated - it is the right thing to do.' While awareness is increasing over the importance of the built environment, physicians seldom consider the environment when promoting 'Exercise as Medicine' with a patient. ${ }^{11}$ Conversely, how often do city planners and engineers think about health issues when making transportation investment and land use decisions? The time has come to reconcile the two solitudes of urban geography and public health.

\section{CONNECTIVITY-SMOOTH TRANSITIONS}

Have you wanted to take a bus to avoid parking hassles but were put off by the bus connection? The bus does not run on time? You consider it unsafe to make the return trip later in the dark? The City of Vancouver recently upgraded its Transportation Plan to improve facilities for cycling and transit. There was no effort to facilitate private car access. The mantra is that the car should be the 'third choice' (after active transport and transit). Access for all or 'universal access' requires transit vehicles to be designed to accommodate the disabled or less mobile. Floor-level vehicle loading, shelters from excessive sun and rain, and demand-responsive forms of transit service (Dial a Ride) are ways to provide this access. Although 'paratransit' takes patients to visit health professionals, it can serve as a way of connecting seniors to other forms of transit. Multistakeholder coalitions have been effective in creating political prescriptions in farsighted jurisdictions such as Minneapolis, Vancouver and London.

\section{HOUSING MIX AND AFFORDABILITY}

Interestingly, most walkable places were developed before 1950 when the postwar auto era took full hold. Now, there is arguably an undersupply of walkable places. ${ }^{12}$ Walkability's vogue is demonstrated by increased land value and housing prices in the more walkable areas of each region..$^{13}$ As many who want to live in walkable places are being priced out, efforts are needed to provide a range of housing types and price points in the most walkable places. This is particularly important for those who do not have access to cars or can no longer drive. Safe, clean and affordable housing is a primary health concern and belongs on the public health agenda.

Medium- and high-density living is regaining favour due to the recognition that providing local access to services and reduced reliance on cars can help to address a myriad of leading public policy concerns. Reduced air pollution and greenhouse gas emissions, reliance on fossil fuels and clean energy policy, and increased physical activity all converge in the walkability debate. Walkability requires transit investments for regional mobility and infrastructure within communities to support local walking and biking.

Unfortunately, most health and environmental costs resulting from major transportation investments are 'hidden.' In The Hidden Health Costs of Transportation, ${ }^{14}$ the American Public Health Association calls for the accounting of these costs within the transportation planning process. However, 'walking the talk' requires establishing a transportation investment process where near and longer-term costs and quality-of-life issues spanning health and planning are fully integrated. A future may be approaching where housing policy is recognised as transportation policy and where transportation and land use policy is seen as health policy.

\section{THIS ISSUE!}

This BJSM includes the experts' views on plasma-rich protein ${ }^{15}{ }^{16}$ (see pages 616-19) and shoulder guru Ann Cools on tennis injuries (see page 678) ${ }^{17}$ In next month's Warm up, BJSM's Senior Associate Editor Steven Stovitz reports on the American College of Sports Medicine meeting in Baltimore which included a big focus on Exercise is Medicine (http:// podcasts.bmj.com/bjsm/).

Provenance and peer review Commissioned; not externally peer reviewed.

The reference list is published online only at http://bjsm. bmj.com/content/9

Accepted 7 June 2010

Br J Sports Med 2010;44:615. doi:10.1136/bjsm.2010.076265 